\title{
Collaborative M-Learning Adoption Model: A Case Study for Jordan
}

\author{
http://dx.doi.org/10.3991/ijet.v9i8.3639 \\ M.M. Alnabhan, Y. Aljaraideh \\ Jerah University, Jordan
}

\begin{abstract}
This work investigates university students' acceptance and readiness for adopting collaborative and context-aware mobile learning services. An acceptance evaluation study was conducted to identify challenges affecting successful implementation and adoption of collaborative mlearning system. The acceptance study has focused on learning contextual factors and learners requirements available at developing countries, where Jordan was considered as the case of this research. Results have confirmed that learning style, mobile device capability and perceived ease of use are having the most positive contribution towards learners' behavior to use collaborative m-learning services. In light of the achieved results, this work provides a new user acceptance model focused toward the adoption of collaborative m-learning services. Finally, this research draws fundamental recommendations allowing for learning context adaptation and successful collaborative m-learning services implementation.
\end{abstract}

Index Terms-Key words: mobile, learning, collaborative, acceptance, context, adoption.

\section{INTRODUCTION}

The capability and accessibility of mobile technology is rapidly increasing. This resulted for mobile devices to be utilized in the educational context [1]. Using mobile technology improves students learning experience and performance. This is achieved by providing extendable learning environments, and by motivating adaptive collaborative learning outside the classroom context. Accordingly, mobile learning (m-learning) has witnessed an increased attention offering new features and facilities to the teaching and learning process [2]. Many advantages exist from using m-learning; this includes anywhere and anytime learning content access, increased learning users interaction, context-aware and personalized learning. In addition, m-learning reduces accessibility barriers between learners by allowing collaborative and shared learning to take place.

Mobile learning becomes interactive after being implemented in a collaborative environment. Collaborative learning is more visible in m-learning considering the mobility features offered by mobile devices. The common definition of collaborative learning is: "a situation in which two or more people learn or attempt to learn something together" [3]. The successful implementation of collaborative learning depends on three main factors: learning context description, methods of collaboration, and level of participation. Collaborative learning is conducted in different scenarios; formally (e.g. sharing course material) or socially, where students interact and participate in a synchronized learning activity (e.g. joint problem solving). Similarly, collaborative learning can be conducted via virtual communities, where students can interact over available communication infrastructure and form a social network or community.

A considerable attention has been carried out on measuring determinants influencing the adoption of collaborative m-learning systems. This indicates end-users acceptance and readiness of the system [4].This also includes understanding context behind implementing collaborative learning technologies within educational environment. The learning context includes users' preferences and capabilities, technology infrastructure, learning requirements, styles and patterns, and surrounding environmental conditions. This work presents an integrated collaborative m-learning system prototype to be used for enduser acceptance and readiness measurements. Accordingly, this research aims to achieve the following objectives:

- Determine the acceptance and readiness of students towards using collaborative m-learning, and establish factors influencing their acceptance level. This objective is accomplished via answering the following research question:

- Q1: What is the perceived ease of use, perceived usefulness, trust and behavioral intention to use collaborative m-learning among students at Jaresh University, Jordan?

- Utilize personal initiatives, characteristics and preferences, as well as available technology infrastructure, in order to describe learning contextual factors affecting students' behavioral intention to use collaborative m-learning.

- Q2: Is there a statistical significant difference in the intention to use collaborative m-learning, taking into consideration context variables, and personal initiatives such as learning style, mobile device capability and internet connectivity type?

- Identify students' expectations towards collaborative m-learning services and understand challenges affecting successful implementation and adoption of these services.

- Q3: What is the effect of perceived usefulness, perceived ease of use, , and trust on the behavioral intention to use collaborative m-learning?

- Describe a new user acceptance model used for measuring successful adoption of collaborative mlearning system. This model includes a set of interrelated variables having a positive effect towards developing the intention to use collaborative m-learning services. 
This paper is structured as follows; section 2 describes the literature study carried out to conduct this research work; section 3 illustrates the proposed location-based learning model; section 4 provides details of the evaluation framework being utilized. Section 5, describes the research instrument and study sample. Section 6 analyses and discusses achieved results, and presents new collaborative learning acceptance model. Finally, section 7 concludes this work and provides important recommendations for future m-learning systems implementations

\section{LITERATURE BACKGROUND}

Mobile technology is considered as the main component facilitating the development of social and collaborative learning skills. For example, Bluetooth, WI-Fi and mobile broadband are found in most cell phones allowing for the creation of wireless connectivity between endusers supporting collaborative learning activities [5]. Many researchers have discussed the benefits of mobile collaborative learning in improving and easing teaching and learning activities [3]. In [6] advantages of utilizing collaborative m-learning services is described within the educational environment; this includes allowing users to have continuous and ubiquity access to learning content, and enhancing the interaction between students and tutors. Moreover, [7, 8, 9] have investigated advantages of collaborative m-learning with comparison to noncollaborative m-learning. It was confirmed by [10], that collaborative learning motivates learners' interaction and improves learning performance. In addition, this study indicates that utilizing m-learning offers additional informal and fixable learning environments to students. With reference to the collaborative m-learning implementation, [11] present an implantation framework for multimedia content generation and interaction between learners. A different framework was presented in [12], in which a client-server based approach, providing substantial collaboration activities, such as exchange and sharing of learning content between students and online groups discussions. In addition, a layering approach was considered in [13], in which an adaptive collaborative m-learning model was presented consisting of four operational layers; mobile technology, activity, theory and design layer.

Although of the increased mobile technology advancement, still users are facing some challenges in utilizing this technology for accessing and delivering knowledge. Hence, the successful adoption of m-learning is being considered in several studies. Research presented in $[14,15]$, have determined end-users acceptance of mlearning systems, and described variables influencing system usage such as perceived usefulness and perceived ease of use. In the same concern, [16,17] have described the moderating effect of demographical variables on intention to use m-learning. Factors affecting the implementation of m-learning technology are presented in [18], this study also explores students' readiness towards this technology. Similarly, [19] has measured students' perception of M-learning and confirmed its effectiveness and flexibility to increase access to learning resources. In addition, [20] have considered students' capability of using mobile devices features as an important factor for adopting $\mathrm{m}$ learning. In addition, the usability of mobile technology in supporting learning activities is measured and confirmed in [21], taking into consideration device's capability advances and drawbacks.
Accordingly, several research works have been conducted to investigate the perceptions of utilizing mlearning within educational environments. However, only few studies have focused towards considering details of learning context in the implementation and adoption of collaborative m-learning in developing countries. This research investigates students' readiness and acceptance of utilizing m-learning, taking into account contextual factors affecting the achievement of collaborative and interactive learning. This work has been conducted considering educational demographics available at developing countries, in which, Jordan was the focus of the study.

\section{COLLABORATIVE M-LEARNING SYSTEM PROTOTYPE}

The ubiquitous characteristics and enhanced networking capabilities of mobile technology have allowed for advanced social interactions between users, allowing them to engage in personal learning and collaborative experiences. Collaboration is coordinated and synchronous learning activity that maintains a continuous bridge between learners for interaction and for information exchange. An important factor in collaborative learning is the learning context, which is described as any information used to define the situation and components of learning activity. Figure (1), describes the context environment behind collaborative m-learning, which is presented as an interaction between four environments involved in the learning activity life cycle. This includes learners' environment, mobile technology environment, social networking and learning resources environments. Learning activity life cycle undergoes several steps, including:

- Learning service request.

- Context adaptation.

- Resource and content construction.

- Learning service delivery.

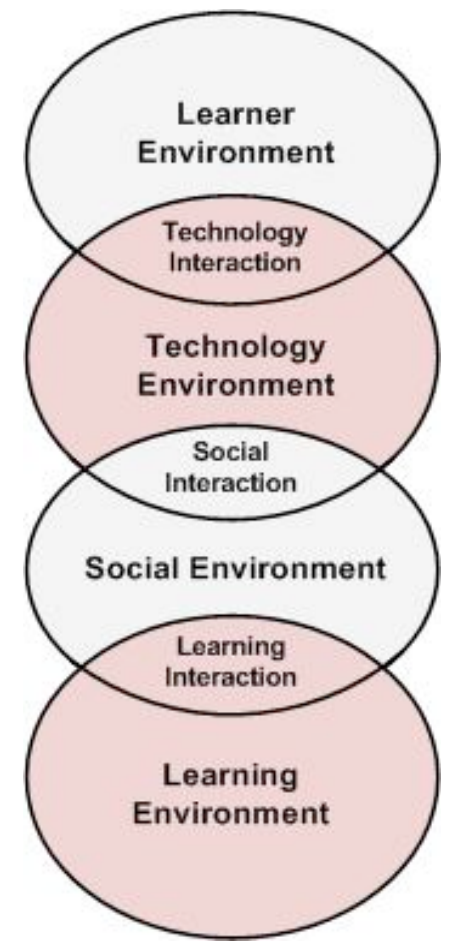

Figure 1. collaborative m-learning context description 


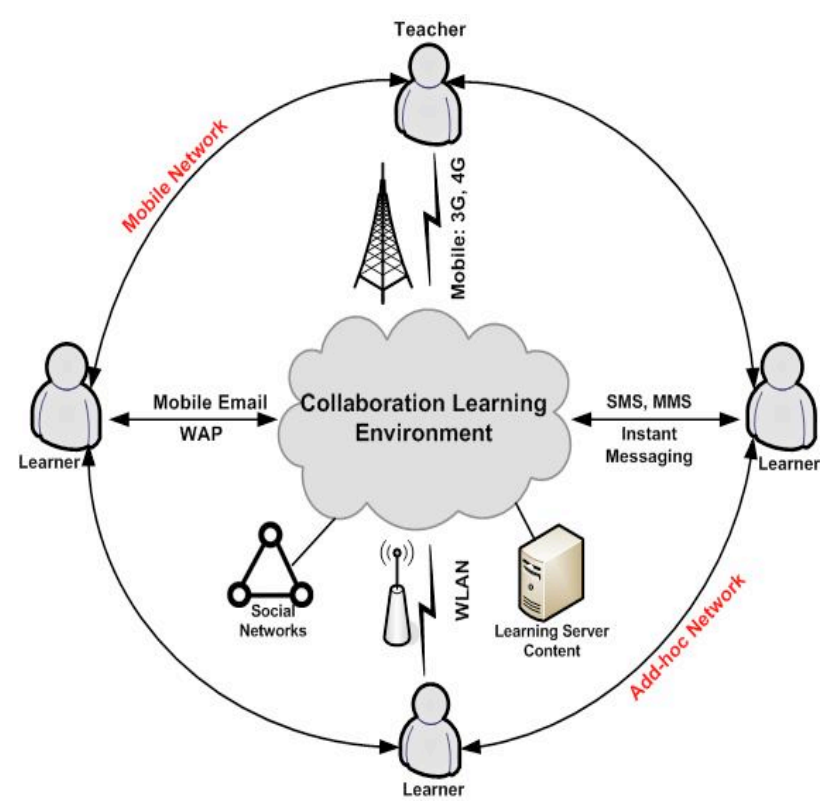

Figure 2. Collaborative m-learning system prototype

Figure (2) presents integrated collaborative m-learning system architecture to be used in the acceptance and readiness study conducted in section (4). The described architecture consists of four major components; users, communication technology, data and services. End users can be either learners or tutors; each has different requirements and capabilities. The mobile communication technology is considered a major component required for successful implementation of collaborative learning. This component facilitates the connection between end users, and allows for learning resources accessibility. Figure (2) shows examples of using mobile and wireless technology protocols, services and applications (e.g. MMS, Instant Messaging, Emails, Social Media Applications) allowing users to interact together and share learning services and resources. For example, concurrent instant messaging and interactive social networks provides learners with increased awareness of available learners allowing the capability of forming group learning. Add-hoc connectivity allows endusers to communicate and access services and resources using mobile devices regardless of their current location and their reference station.

Learning services can be divided into three modules; collaborative service module, peer-to-peer service module, and server-based module. Collaborative services are considered interactive enabling learners to send and receive message, sharing information and resources, forming learning communities and conduct group tasks. In some cases, collaborative services require the knowledge of learners' location in order to search for users within the learning group. Peer-to-peer services require two users' peers (student - student, student - tutor) to be directly connected sharing learning resources and experience. Server-based services require a remote connection to the content sever obtaining required learning resources. Notification services are considered as an example of serverbased learning services.

\section{EVALUATION FRAMEWORK}

In this work, Mobile Services Acceptance Model (MSAM) is utilized in order to evaluate the proposed collaborative m-leaning model in terms of users' acceptance and readiness. This model was presented in [22] and is based on Technology Acceptance Model (TAM), Unified Theory of Acceptance and Use of Technology (UTAUT), Innovation Diffusion Theory (IDT) and Theory of Planning Behavior (TPB). The MSAM describes several factors influencing the adoption of mobile applications; this includes personal initiatives and characteristics, context, trust, perceived ease of use and perceived usefulness. These components are described as follows:

- Personal Initiatives and Characteristics: this factor is used to define users' motivation and capability to utilize new applications such as mobile applications. Considering m-learning, this factors includes the following:

- Personal characteristics such as; gender, age, capabilities and needs.

- Educational background, skills and expertise.

- Learning history, preferences and styles.

- Context: this factor refers to users' location, state, and available resources and surrounding physical objects. This includes information about mobile technology being utilized; network connectivity and mobile device capability. Contextual information is considered crucial in determining requirements for $\mathrm{m}$ learning successful implementation.

- Trust: this factor measures the degree of user's belief on the security of a specific mobile application. Trust can be considered as a predictor of users' behavioral intention to employ m-learning systems within the teaching and learning process.

- Perceived Usefulness (PU): this factor is used to describe the level to which an individual believes that utilizing the system will help improving job performance. This factor is also used to measure user's behavior towards accepting and adoption a new system. With reference to m-learning, this factor allows measuring how learners will find m-learning system useful in completing learning activates efficiently and flexibly.

- $\quad$ Perceived Ease of Use (PEU): this factor describes the level to which a user believes that using a system would be simple and with less effort. Hence, if a user is experiencing challenges in using a mobile application, then he will be reluctant in using that application [23]. Considering m-learning, if the learner is satisfied with the simplicity of m-learning system, this indicates a high degree of system acceptance for usage.

- Intention to Use: this factor measures the user's or learner's intention to use the mobile application.

\section{V.RESEARCH INSTRUMENT:}

An intensive questionnaire was designed taking into consideration the acceptance evaluation model described in the previous section. This questionnaire was administrated for evaluating end-user acceptance and readiness towards collaborative m-learning services. The questionnaire has 33 items distributed among four domains ac- 
cording to acceptance model components. Trust has six items, perceived usefulness has five items, perceived ease of use has five items, context has six items, personal initiatives have six items, and behavioral intention with five items. The questionnaire consists of two main question types. A 5-point Likert scale used to describe respondents' perception towards intended M-learning services. This question type was focused on testing perceived ease of use, perceived usefulness, trust and intention to use factors. The second type was open ended questions, and was designed in order to obtain information about students' learning styles; in which three categories were determined; interactive learning, peer-to-peer learning, and passive learning. The open ended questions were focused towards a set of learning scenarios corresponding to the learning styles categories being investigated.

\section{A. Study Sample}

This study was conducted at Jerash University, Jordan. Students in different undergraduate levels from Information Technology (IT), Science and Education faculties were requested to complete the questionnaire described in the previous section. A total of 180 students have participated in the study. IT students were the largest respondents group $(55 \%)$ followed by $(30 \%)$ of education students and (15\%) science students. Demographic characteristic of participating students and the learning context are shown in table (1).

As shown in Table (1), the percentage of male respondents was $46 \%$, whereas $54 \%$ of them were female. Moreover, $76 \%$ of responding students were utilizing Smartphones and nearly $24 \%$ are using standard normal phones. With reference to internet connectivity, the majority of students (103) where accessing internet via mobile networks, while (77) students used "Wifi" to connect to internet. This increase in Smartphone and mobile internet connectivity employment had a dramatic affect on the adoption of mobile learning activities. In terms of the learning style, the percentage of students classified as interactive learners was $(46 \%)$, while $(33 \%)$ of students were classified as peer-to-peer learner. Passive learners constructed around (21\%) of the sample of the study.

\section{B. The Validity and Reliability of Instrument}

In order to measure internal validity of the research instrument being used, a factors analysis study was conducted, and results are presented in Table (2)

The validity of the instruments was measured using SPSS data reduction techniques. Factor analysis procedure was used with principal components analysis. High values of KMO test (close to 1.0) generally point out that factor analysis may considered useful with the data of this study (KMO is $.787>0.50)$. The Bartlett's test of sphericity (Homogeneity of covariance) is 3367.7 and statistically significant at $p<0.05$. This indicates a significant relationships among the variables of the study as well as the scale has good validity [24].

\section{RESULTS ANALYSIS AND DISCUSSION:}

Results of descriptive analysis and Cronbach's Alpha measurements are described in Table (3). This analysis was conducted on the acceptance model factors answering the first research question: What is the perceived ease of use, perceived usefulness, trust and behavioral intention to use mobile learning among students at Jaresh University?
TABLE I.

THE SUBJECTS' DEMOGRAPHIC CHARACTERISTICS (PERSONAL CHARACTERISTIC AND CONTEXT FACTORS)

\begin{tabular}{|c|c|c|c|}
\hline Variables & Type & Number (N) & Percentage (\%) \\
\hline \multirow{4}{*}{ Gender } & Male & 97 & $54 \%$ \\
\cline { 2 - 4 } & Female & 83 & $46 \%$ \\
\hline \multirow{3}{*}{ Specialization } & $\begin{array}{c}\text { Information Tech- } \\
\text { nology }\end{array}$ & 99 & $55 \%$ \\
\cline { 2 - 4 } & Education & 54 & $30 \%$ \\
\cline { 2 - 4 } & Science & 27 & $15 \%$ \\
\hline \multirow{2}{*}{$\begin{array}{c}\text { Mobile Device } \\
\text { Type }\end{array}$} & Smart Phone & 149 & $76.2 \%$ \\
\cline { 2 - 4 } & Normal Phone & 31 & $23.8 \%$ \\
\hline $\begin{array}{c}\text { Internet Con- } \\
\text { nectivity }\end{array}$ & Mobile Broadband & 103 & $57.2 \%$ \\
\cline { 2 - 4 } & Wifi & 77 & $42.8 \%$ \\
\cline { 2 - 4 } & Interactive learning & 83 & $46 \%$ \\
\cline { 2 - 4 } & Peer-to-peer learn- & 60 & $33 \%$ \\
\cline { 2 - 4 } $\begin{array}{c}\text { Learning Style } \\
\text { ing }\end{array}$ & Passive learning & 37 & $21 \%$ \\
\hline
\end{tabular}

TABLE II.

ACCEPTANCE MODEL FACTORS ANALYSIS FOR INSTRUMENT VALIDITY

\begin{tabular}{|c|c|c|c|c|}
\hline Factors & Question & Factor lading & KMO & Sig \\
\hline \multirow{5}{*}{ Perceived usefulness (PU) } & $\mathrm{Pu} 1$ & .753 & \multirow{21}{*}{.787} & \multirow{21}{*}{.000} \\
\hline & $\mathrm{Pu} 2$ & .726 & & \\
\hline & $\mathrm{Pu} 3$ & .703 & & \\
\hline & $\mathrm{Pu} 4$ & .689 & & \\
\hline & Pu5 & .687 & & \\
\hline \multirow{5}{*}{$\begin{array}{l}\text { Perceived ease of use } \\
\text { (PEOU) }\end{array}$} & Peou1 & .674 & & \\
\hline & Peou2 & .668 & & \\
\hline & Peou3 & .569 & & \\
\hline & Peou4 & .534 & & \\
\hline & Peou5 & .709 & & \\
\hline \multirow{6}{*}{ Trust } & $\mathrm{T} 1$ & .701 & & \\
\hline & $\mathrm{T} 2$ & .593 & & \\
\hline & $\mathrm{T} 3$ & .711 & & \\
\hline & $\mathrm{T} 4$ & .647 & & \\
\hline & T5 & .532 & & \\
\hline & $\mathrm{T} 6$ & .647 & & \\
\hline \multirow{5}{*}{$\begin{array}{l}\text { Behavioral intention to } \\
\text { use (BIU) the Mobile } \\
\text { learning system }\end{array}$} & BIU1 & .860 & & \\
\hline & BIU2 & .732 & & \\
\hline & BIU3 & .775 & & \\
\hline & BIU4 & .742 & & \\
\hline & BIU5 & .763 & & \\
\hline
\end{tabular}

TABLE III.

DESCRIPTIVE ANALYSIS AND CRONBACH'S ALPHA VALUE

\begin{tabular}{|l|c|c|c|}
\hline \multicolumn{1}{|c|}{ Acceptance Model Factors } & Mean & SD & Alpha \\
\hline Perceived usefulness (PU) & 3.9 & .54 & .93 \\
\hline Perceived ease of use (PEOU) & 3.7 & .44 & .91 \\
\hline Trust & 3.2 & .60 & .86 \\
\hline $\begin{array}{l}\text { Behavioral intention to use (BIU) } \\
\text { the collaborative m-learning system }\end{array}$ & 3.0 & .71 & .91 \\
\hline
\end{tabular}


As shown in table 3 , all means scores were $(>3.0)$ of the midpoint, ranging from 3.0 to 3.9 . Hence, an overall positive response to the model factors is indicated. The standard deviation (SD) values showed a narrow spread around the mean which indicate a harmony between the members of the sample. In addition, table 3 shows that Cranach's alpha value is ranging from .86 to .93 , indicating good scale reliability[24].

An independent sample t-test and ANOVA analysis were demonstrated to measure the statistical differences in the intention to use collaborative m-learning, taking into consideration learning context variables and personal characteristics. This analysis study was conducted in order to answer the second research question: Is there a statistical significant difference in the intention to use collaborative m-learning, taking into consideration context variables, and personal initiatives such as learning style, mobile device capability and internet connectivity type?

As described earlier, available resources and infrastructure are considered as a main of the learning context. Table (4) below describes the statistical differences for intention to use collaborative m-learning considering internet connectivity and mobile device types and capabilities.

Accordingly, results have shown no statistical difference in the mean intention to use mobile learning taking into account internet connectivity type. This can be explained from the availability and accessibility of both internet connectivity types by learning users. However, a statistically difference in the mean intention to use collaborative m-learning was measured while considering mobile devices' types and capability. The favor was for Smartphones t $(178)=3.77$ which was significant at 0.05 confidence level. This was due to the capability and functionality of Smartphone devices, allowing the use of advanced applications, and facilitating the accessibility of several types of learning services. In addition, students using Smartphones are more familiar and capable of using mobile learning applications, comparing with standard phone users. This result confirms with [20].

Learning styles distribution among participating students according to their educational backgrounds or university faculty is shown in Table (5).

The above table shows that the majority of information technology students are classified as interactive learners flowed by science students and education students. This was due to the familiarity of IT students on the technical requirements behind achieving interactive learning. Also, the nature of courses and teaching methods employed within applied science faculties involve using elements of interactive learning. A one way ANOVA test study was demonstrated in order to measure the effect of the learning style variables on the intention to use m-learning. Table (6) describes the statistical differences for intention to use by participating students based on their learning style.

It was determined that there is a significant differences in the intention to use collaborative m-learning considering the learning style types, F $(5.179)=5.32$, in favor of interactive learning. This was due to the nature of interactive learning that provides students the chance to participate in the teaching and learning activities. In addition, elements of interactive learning such as; shared learning resources, matching learners, and competent learning environments attract students' attention.
TABLE IV.

GROUP DIFFERENCES FOR INTENTION TO USE M- LEARNING BY JORDANIAN STUDENTS BASED ON INTERNET CONNECTIVITY AND PHONES' TYPE (INDEPENDENT-SAMPLE T-TEST)

\begin{tabular}{|c|c|c|c|c|c|c|}
\hline $\begin{array}{l}\text { Context } \\
\text { variable }\end{array}$ & Type & $\mathbf{N}$ & $\mathbf{M}$ & SD & $\mathbf{T}$ & Df \\
\hline \multirow{2}{*}{$\begin{array}{c}\text { Internet } \\
\text { Connectivity }\end{array}$} & $\begin{array}{l}\text { Mobile Broad- } \\
\text { band }\end{array}$ & 103 & 3.9 & .62 & \multirow{2}{*}{1.84} & \multirow{2}{*}{178} \\
\hline & Wifi & 77 & 3.6 & .49 & & \\
\hline \multirow{2}{*}{$\begin{array}{l}\text { Mobile De- } \\
\text { vice Type }\end{array}$} & Smartphone & 149 & 3.3 & .55 & \multirow{2}{*}{$\begin{array}{c}3.77 \\
*\end{array}$} & \multirow{2}{*}{178} \\
\hline & Standard Phone & 31 & 3.1 & .53 & & \\
\hline
\end{tabular}

TABLE V.

DISTRIBUTION OF FACULTIES' STUDENTS ACCORDING TO THEIR LEARNING STYLE

\begin{tabular}{|c|c|c|c|c|c|c|}
\hline \multirow{2}{*}{$\begin{array}{c}\text { Back- } \\
\text { ground }\end{array}$} & $\begin{array}{c}\text { Interactive } \\
\text { Learning }\end{array}$ & $\%$ & $\begin{array}{c}\text { P-P } \\
\text { Learning }\end{array}$ & $\%$ & $\begin{array}{c}\text { Passive } \\
\text { Learning }\end{array}$ & $\%$ \\
\hline $\begin{array}{c}\text { Information } \\
\text { Technology }\end{array}$ & 35 & 58.4 & 15 & 25 & 10 & 16.6 \\
\hline Science & 25 & 41.6 & 19 & 31.7 & 16 & 26.7 \\
\hline Education & 23 & 38.4 & 17 & 28.3 & 20 & 33.3 \\
\hline Total & 83 & 46.1 & 51 & 28.3 & 46 & 25.6 \\
\hline
\end{tabular}

TABLE VI.

GROUP DIFFERENCES FOR INTENTION TO USE MOBILE LEARNING BY JORDANIAN STUDENT BASED ON THEIR LEARNING STYLE (ONE-WAY ANOVA)

\begin{tabular}{|l|l|l|l|c|}
\hline \multicolumn{1}{|c|}{ Variable } & \multicolumn{1}{c|}{ M } & \multicolumn{1}{c|}{ SD } & F & Df \\
\hline Learning Style & 3.6 & .59 & $* 5.32$ & 5.179 \\
\hline Interactive learning & 3.3 & .45 & & \\
\hline Peer-to-peer learning & 3.2 & .53 & & \\
\hline Passive learning & 2.9 & .82 & & \\
\hline
\end{tabular}

TABLE VII.

MULTIPLE REGRESSION (MODEL SUMMARY) ANALYSIS RESULTS

\begin{tabular}{|c|c|c|c|c|c|c|}
\hline Predictor & $\mathbf{B}$ & Beta & $\mathbf{t}$ & Sig & $\mathbf{R}^{2}$ & Contribution \\
\hline PEOU & .61 & .54 & 1.7 & .001 & .51 & $51 \%$ \\
\hline PU & .19 & .27 & 1.1 & .000 & .22 & $22 \%$ \\
\hline Trust & .12 & .09 & 4.1 & .007 & .06 & $6 \%$ \\
\hline
\end{tabular}

Multiple regression analysis was used to measure the strength of independent variables (perceived ease of use, perceived usefulness and trust) toward dependent variable (Behavioral intention to use (BIU) the collaborative $\mathrm{m}$ learning system. This analysis study was carried out in order to answer the third research question: What is the effect of perceived ease of use, perceived usefulness, and trust on the behavioral intention to use collaborative $m$ learning?. Table (7) displays results of the multiple regression analysis.

The ease of use yielded $(\beta=0.61, t=1.7)$ at significant level $(\mathrm{p}=0.00<0.05)$ and predicts $51 \%$ upon intention to use. This means that if the score of 'ease of use' increases to 1 unit, the intention to use will increase .61 units. Perceived usefulness as independent variable yielded values $(\beta=.19, \mathrm{t}=1.1)$ at significant level $(\mathrm{p}=0.00<0.05)$ and predicts $22 \%$ upon intention to use. This means that if the score of 'Perceived usefulness' increase 1 unit the intention to use will increase .19 units. Finally, trust predicts $6 \%$ upon intention to use. Consequently, the ease of use is 
considered as the most important variable with the highest contribution and affect to the intention to use the collaborative $\mathrm{m}$-learning by students at Jaresh University.

According to previously described results and analysis, it was confirmed that learning context and personal initiatives have direct effect on the intention to use collaborative m-learning services. A statistical significance was measured while considering learning styles and mobile devices capability. In which, interactive learners and Smartphone users have shown a positive status towards using collaborative m-learning. Results have confirmed a significant relationship between student educational backgrounds (personal initiatives) and learning style. IT students considered to have the highest positive attitude to use collaborative m-learning services. In addition, ease of use was confirmed to have highest contribution to the intention to use collaborative m-learning services, comparing to other acceptance components. Learning context understating and personal initiatives adaptation are main imposing challenges towards adoption and successful implementation of collaborative m-learning in Jordanian Universities. A new acceptance model used for measuring the successful implementation of collaborative m-learning services is presented in figure (3). This model is designed and demonstrated taking into consideration results described earlier in this work. In which, it considers factors having highest contribution to the intention to use collaborative m-learning services. In addition the new model focuses on learning context details with direct effect to the services usage acceptance.

The proposed model consists of two main components, the learning context and system acceptance determinants. The learning context consists of two interrelated parts, learners' requirements and technology infrastructure. Learners' requirements include learners' preferences and capability; these describe learning styles, educational background, and learning users' capacity. Learning context also includes communication technology infrastructure and specifications; mobile device features (software and hardware), and mobile network characteristics (type, range, and performance). The learning context variables are measured having positive contribution towards users' acceptance of collaborative m-learning. The second model component consists of technology acceptance variables; perceived usefulness and perceived ease of use. In which, both variables have a direct effect to the intention to use.

\section{CONCLUSION AND RECOMMENDATIONS}

This work measures university students' acceptance towards utilizing and adopting collaborative m-learning services. A prototype for an integrated collaborative mlearning model was described and utilized during the acceptance evaluation process, allowing students to understand system functionality, existing context, and available learning services. The acceptance evaluation study has adopted Mobile Services Acceptance Model (MSAM) in order to identify challenges affecting successful implementation of collaborative m-learning services, taking into consideration a set of learning context variables and learners requirements available within Jordanian educational environment, where Jerash University was considered a the case for this study. Results have shown that both user acceptance and learning context factors are having positive contribution towards using collaborative m-learning services. This includes learning style, mobile device capa-

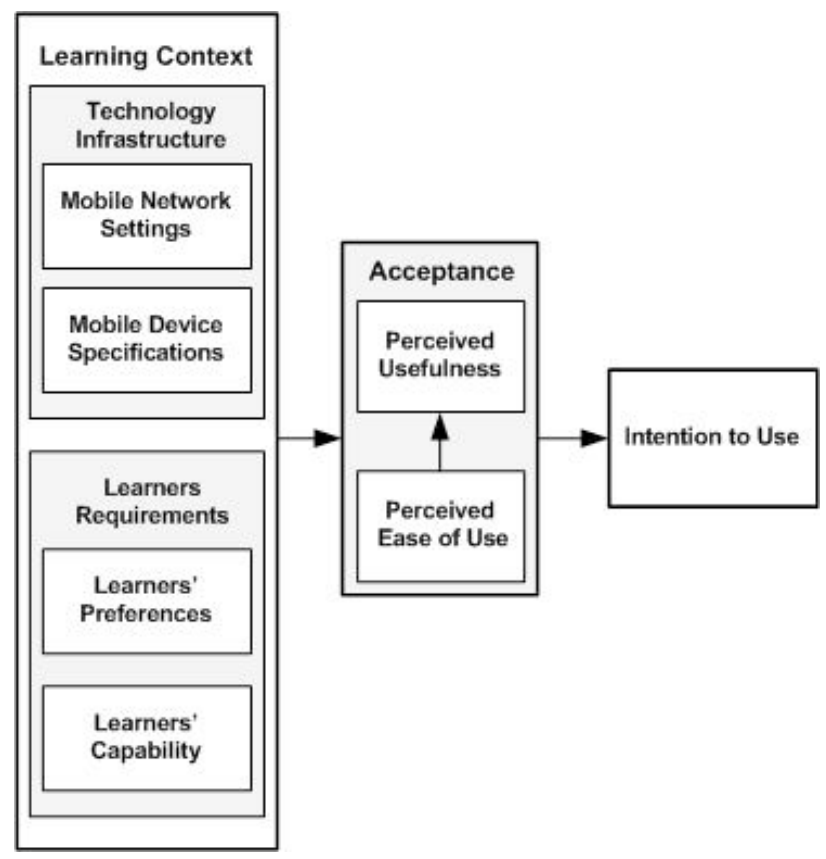

Figure 3. Proposed collaborative m-learning acceptance model

bility and services perceived ease of use. More especially, it was confirmed that interactive learners using Smartphone devices and coming from Information Technology backgrounds will be more constructive for adopting collaborative m-learning services. In light of the results and analysis study, this work presented a new user acceptance model used for measuring successful implementation and adoption of collaborative m-learning system. This model is considered distinctive because it includes detailers for a set of interrelated variables having direct impact on improving the intention to use collaborative m-learning services. Based on the previous conclusions the following recommendations are presented:

- More attention to interactive learning style is required when designing and developing mobile learning systems.

- Educational institutions in developing countries have to adopt new policies allowing the integration of collaborative and interactive teaching and learning methods within the educational structure. This will increase the awareness and readiness of collaborative M-learning services.

- Learning context understating and adaptation is considered as the main imposing challenges towards adoption and successful implementation of collaborative m-learning in Jordanian Universities. Hence, students' preferences, capabilities and available technological infrastructure have to be considered during all m-learning system development stages.

\section{REFERENCES}

[1] Khaddase, F., Lanham, E., \& Zhow, W. (2009). A mobile learning model for universities re- belnding the current learning environment. International Journal of Interactive Mobile Technologies, 3(1), 18-23.

[2] Jacob, S. M., \& Issac, B. (2008). Mobile technologies and its impact- An analysis in higher education context. International Journal of Interactive Mobile Technologies, 2(1), 10-18.

[3] Cruz-Flores, R., \& Lopez-Morteo, G. (2008). A Model for Collaborative Learning Objects Based on Mobile Devices. In Com- 
puter Science, 2008. ENC '08. Mexican International Conference on (pp. 89-95). http://dx.doi.org/10.1109/ENC.2008.32

[4] BankPhua, C. Wong, P. Abu, S. (2012). Factors influencing the behavioral intention to use the internet as a teaching-learning tool in home economics. Social and Behavioral Sciences, 59,180187.

[5] Ferro, E., \& Potorti, F. (2005). Bluetooth and Wi-Fi wireless protocols: a survey and a comparison. Wireless Communications, IEEE, 12(1), 12-26. doi: 10.1109/MWC.2005.

[6] Corbeil J. R., \& Valdes-Corbeil, M. E. (2007). Are you ready for mobile learning?, Educause Quarterly, 30(2), 51-58.

[7] Attewell, J., \& Savill-Smith, C. (Eds.). (2004). Learning with mobile devices: Research and development- A book of papers. London, UK: Learning and Skills Development Agency. International Journal of Mobile and Blended Learning, 4(4), 1-20, October-December 201215

[8] Zurita, G. \& Nussbaum M. (2007). A Conceptual Framework Based on Activity Theory for Mobile CSCL. British Journal of Educational Technology, $38 \quad$ (2), 211-235 http://dx.doi.org/10.1111/j.1467-8535.2006.00580.x

[9] Razaque A. and Elleithy, K. (2011). Architecture based Prototypes for Mobile Collaborative Learning to improve Pedagogical activities. Interactive collaborative learning (ICL), IEEE, Piešany, Slovakia, September 21 - 23, 2011. http://dx.doi.org/10.1109/ ICL.2011.6059544

[10] Lam, P. Wong, K. Cheng, R. Ho, E. \& Yuen, S. (2011). Changes in students mobile learning readiness-Comparison of survey data collected over a nine- month period. In Proceedings of the Global Learn Asia Pacific, Melbourne, Australia (pp.180-189).

[11] Xiaoyong Su, B.S.Prabhu, Chi-Cheng Chu, Rajit Gadh, "midleware for multimedia mobile collaborative system", IEEE third annual wireless telecommunications symposium (WTS, 2004), May 14-15, 2004, Calpoly pomona, Clofornia, USA.

[12] Razaque, A. Elleithy, K. Salama, N. (2012). Novel Framework for Mobile Collaborative learning (MCL)to substantiate pedagogical activities. CoRR abs/1210.2023 (2012)

[13] Hamdan, N.A. Schaper, H. (2012). Collaboration in Mobile Learning, Seminar on Mobile Learning, Computer-Supported Learning Research Group, Germany, march 2012

[14] Alksasbeh, M. (2012). Integrating mobile technology quality service, trust and cultural factors into technology acceptance of mobile learning: A case of the Jordan higher education institution. PhD thesis, University Utara Malaysia, Malaysia.

[15] Nassuora, M. (2012). Students acceptance of mobile learning for higher education in Saudi Arabia. International Journal of Learning Management Systems, 1(1), 1-9. http://dx.doi.org/10.12785/ ijlms $/ 010101$

[16] Teo, T. (2010). Efficiency of the technology acceptance model to explain pre-service teachers' intention to use technology. A Turk- ish study. Campus Wide Information System, 28(2), 93-101. http://dx.doi.org/10.1108/10650741111117798

[17] Wang, Y. Wu, M. \& Wang, H. (2009). Investigating the determinants and age and gender differences in the acceptance of mobile learning. British Journal of Educational Technology, 40(1), 92118. http://dx.doi.org/10.1111/j.1467-8535.2007.00809.x

[18] Abu-Al-Aish, A. Love, S. Hunaiti, Z. (2012): Mathematics Students' Readiness for Mobile Learning, International Journal of Mobile and Blended Learning, 4(4), 1-20. http://dx.doi.org/10.4018/jmbl.2012100101

[19] Al-Fahad, F. N. (2009). Students' attitudes and perception towards the effectiveness of mobile learning on King Saud University, Saudi Arabia. The Turkish Journal of Educational Technology, 8(2), 111-119.

[20] Economides, A. A. \& Grousopoulou, A. (2009). Students' thoughts about the importance and costs of their mobile devices' features and services. Telematics and Informatics, 26(1), 57-84. http://dx.doi.org/10.1016/j.tele.2008.01.001

[21] Calderón, J.F. Bravo, C. Infante C. and Vásquez, A. Echeverría, A. Nussbaum, M. (2011), Face-to-Face Collaborative Learning Supported by Mobile Phones, Interactive Learning Environments, 19 (4), pp.351-363 http://dx.doi.org/10.1080/10494820903232943

[22] Gao, S. Krogstie, J. and Gransæther, P.A. (2008). Mobile Services Acceptance Model. In ICHIT "08: Proceedings of the 2008 International Conference on Convergence and Hybrid Information Technology, Washington, DC, USA, (pp.446-453) http://dx.doi.org/10.1109/ICHIT.2008.252

[23] Sun, P. C., Tsai, R. J., Finger, G., Chen, Y. Y., \& Yeh, D. (2008). What drives a successful e-learning? An empirical investigation of the critical factors influencing learner satisfaction. Computers \& Education, 50 (4), 1183-1202. http://dx.doi.org/10.1016/ j.compedu.2006.11.007

[24] Hair, J. F., Black, W. C., Babin, B. J., Anderson, R. E., \& Tatham, R. L. (2006). Multivariate data analysis: New Jersey: Prentice Hall.

[25] Peng, H. Su, Y. Chou, C. \& Tsia, C. (2009). Ubiquitous knowledge construction: mobile learning re-define and conceptual framework. Innovations in Education and Teaching International, 46(2), 171-183. http://dx.doi.org/10.1080/14703290902843828

\section{AUTHORS}

M. M. Alnabhan is with the Faculty of Information Technology, Jerah University, Jordan.

Y. Aljaraideh is with the Faculty of Education, Jerah University, Jordan.

Submitted 11 March 2014. Published as re-submitted by the authors 26 May 2014 